\title{
Cooperation of IT-park of PetrSU with Russian and International Organizations
}

\author{
Anatoly Voronin, Anton Shabaev
}

\begin{abstract}
The paper provides overview of research and development cooperation established by Petrozavodsk State University (PetrSU) with Russian and Finnish industrial, research and educational organizations. Over the years, PetrSU has developed experience, infrastructure and necessary resources for efficient cooperation with foreign partners, and now successfully collaborates with leading Finnish, Russian and international companies, as well as small and medium-sized enterprises. This cooperation is also closely linked to student education and creativity.
\end{abstract}

Index Terms-Software systems, Mathematical programming, Optimization methods.

\section{INTRODUCTION}

During the past years PetrSU has been transforming from research and educational organization into educational, research and innovation complex, where one of the main goals is implementation of all stages of innovation development, especially in the field of IT. In the rating of Russian Federation Federal Agency for Education PetrSU is among the top 10 universities of Russia in the fields of ICT and international cooperation.

Besides fundamental and pilot research, PetrSU staff participates in end-to-end research and practical development projects for customers and end-users. This work is also closely linked to student education and creativity.

IT-park of PetrSU was founded in 2005 and brought together 23 units of the university within 3 departments -

Manuscript received December 12, 2013; accepted December 12, 2013. Date of online publication: December 15, 2013.

The research component of this activity was supported by grants 14.514.11.4004 and 02.527.11.9021 of the Russian Federal Ministry for Education and Science; grants 17622 and 13704 of Russian Foundation of Support to Small Scientific-Technical Enterprises as well as grants KA179, KA322 and KA432 of Karelia ENPI [10] - joint programme of EU, Russia and Finland. The purchase of required equipment and software licenses was supported by the Program of Innovative Infrastructure Development of Petrozavodsk State University as well as 3 grants and subsidies from the Ministry of Economic Development of Karelia.

The article was published with financial support of the Strategic Development Program of Petrozavodsk State University.

A. Voronin is with the Chair of Applied Mathematics and Cybernetics, Faculty of Mathematics of Petrozavodsk State University, 185910 Petrozavodsk, Russia (e-mail: voronin@psu.karelia.ru).

A. Shabaev is with the Chair of Applied Mathematics and Cybernetics, Faculty of Mathematics of Petrozavodsk State University, 185910 Petrozavodsk, Russia (e-mail: ashabaev@petrsu.ru).
ICT, system engineering, and education technologies in ICT. The staff of all units has 5-35 years of experience in scientific and commercial activity. The total number of staff is about 400 people, including full-time employees $-50 \%$, teaching staff $-25 \%$, students and post-graduate students $25 \%$.

Mission of IT-park is to promote hi-tech products in Nordic countries and the Russian Federation by building on the existing scientific-educational and technological potential of its personnel; by formulating uniform policy, and by coordinating the activity among its entities.

A distinctive feature of IT-park is automation of nontypical and complex business-processes by exploiting mathematical methods to solve complex problems such as optimizing planning and resource allocation, trim, and composition.

IT-park of PetrSU delivers a broad range of IT services to support manufacturing companies, including:

- creating mathematical models for solution of complex enterprise management problems;

- designing algorithms and software packages for optimization problems solution;

- developing, commissioning and maintaining management information and process control systems.

Major customers are largest forestry and pulp-and-paper enterprises of Russia, Russian and international software development companies, Russian and international research and educational institutions, and other organizations.

Joint activity with a number of Finnish companies and research centers is an essential component of PetrSU research, development and educational activity. Together with its Finnish partners, PetrSU performs research, training of students and specialists in software development (with Metso Automation Inc., Outotec Oy, FRUCT Oy, Nokia Research Centre and VTT) and in forestry sector (Finnish Forest Research Institute METLA, Ponsse Plc.).

The cooperation with Russian and Finnish business and educational organizations is an effective factor for development and modernization of scientific and educational capacity of PetrSU and is an important tool for training highly qualified specialists able to work in the global economy and to meet the demands of innovative labor market. 
In Section II we provide an overview of several software systems developed in IT-park for optimal planning and management of forestry sector enterprises of Russia and CIS. In Section III we provide the main directions and milestones of cooperation with Metso Corporation. In Section IV - the main directions and milestones of cooperation with Outotec Corporation. In Section V briefly describe the mobile applications development. Finally, Section VI concludes the paper.

\section{COOPERATION WITH RUSSIAN ENTERPRISES}

Development of software systems for improving production efficiency of industrial enterprises is a part of long-term and diverse research and development activity carried out at PetrSU. The main focus has been on the forestry industry, which is one of the main sectors of Russian economy [1].

Cooperation with Russian enterprises of the pulp-andpaper and forestry industries of USSR, Russia and CIS has been actively developing since 1982. Among the customers are Arkhangelsk, Bratsk, Kiev, Kotlas, Kondopoga, Segezha and Svetogorsk pulp-and-paper mills (which are among 10 largest pulp-and-paper mills in CIS), as well as many other smaller industrial enterprises.

Since 1982 till 2002 software development for industrial enterprises had been carried out by the Department of applied mathematics and cybernetics of PetrSU. Since 2002 the efficiency of customer projects was improved by establishment of PetrSU-Metso Automation Systems Center (PMASC). Since 2011 cooperation of PetrSU with industrial enterprises and other organizations has been further intensified by establishment of Opti-Soft Ltd. and a range of other small innovative companies owned by PetrSU. Altogether since 1982 more than 150 custom software systems (including more than 70 since 2005) have been delivered to industrial enterprises and organizations of Finland, Russia and CIS.

In this paper we describe 5 software systems developed in IT-park for optimal planning and management of forestry sector enterprises. The mathematical models, solution methods and software components, used in the systems, are quite generic and can be utilized at a wide range of enterprises in Russia and abroad. The most popular systems including the following:

- "Corrugated cardboard" - for optimization of corrugated cardboard plants operation.

- "Sawmill" - for optimization of sawmills operation.

- "Loading" - for optimal loading of transportation facilities (trucks, trains and ships).

- "Trim optimization" - for trim optimization during paper machines operation.

- "Plywood" - for optimization of plywood mills operation.
Development of each system is based on quite deep study of the process technology, otherwise planning results would not be efficient (and sometimes even not useful). Integration of the services into existing ICT ecosystem at Customer enterprises is possible.

The use of the systems allows Customer enterprises to noticeably improve efficiency and productivity: reduce the material losses (by 1-3\%), to increase the equipment uptime by $3-4 \%$, and shorten the production planning time (by $1.5-2$ times). Altogether this leads to saving of several hundred thousands euro per year at each mill. The use of the systems also allows customer specialists to model and compare side-by-side various scenarios of production and procurement, and select best and justified scenario, thus improving control over production.

Description of each system follows. Due to lack of space, details of the mathematical models and software implementation are not provided in paper, but they have been published in [1]-[4]. Also demos are available at http://opti-soft.ru/

\section{A. The "Corrugated cardboard" system}

Corrugated cardboard is a cellulose material made up of the combination of several smooth sheets separated equally by one or more corrugated sheets. This structure enables corrugated cardboard to provide maximum protection against bumps as well as supporting heavy weight, while at the same time being a lightweight packaging that is easy to transport and handle.

The line of corrugated cardboard is cut into rectangular pieces at the speed of $160 \mathrm{~m} / \mathrm{min}$. The pieces are used for making boxes. The task of the mill management is to ensure the production of required number of boxes made of several rectangles of different size. As the number of boxes types exceeds 100 per week, and the number of boxes of each type is less than 1000, the material losses increase to 5-6\%, planning time - to several hours, etc. The service uses mathematical methods and optimization algorithms to decrease the material losses and planning time, and increase the equipment uptime.

The target of the service - production of balanced amounts of rectangles of cardboard for making boxes with minimal material losses, considering the production capacity and re-tuning time of equipment, order scheduling and priorities.

The main functions of the service include:

- generation of all feasible cutting orders according to specified types of boxes

- finding the cutting order, which ensures production of required number of boxes, including the warehouse stock

- production optimization according to material losses

- monthly planning of plant operation (target figures may be loaded from other systems)

- price calculation for each type of box 
- tracking the effect of each additional type of box on total plant material losses

- documentation, reporting and archiving

- integration with other systems, including accounting systems, ERP systems, process control systems (e.g., BHS, Dücker, Signode) and other.

The mathematical model of the production planning problem, its features and an overview of solution method for the related optimization problem are provided in [4].

The "local" software system and the corresponding "cloud" service have been successfully installed at 17 enterprises, including the following largest ones:

- OJS "Kiev pulp-and-paper mill" (Obuhov, Ukraine), producing 20 mln.sq.m. monthly

- "Naberejno-Chelninsky cardboard-and-paper mill" Ltd. (Naberejnye-Chelny, Russia), producing 20 mln.sq.m. monthly

- CJS "Gotek" (Zheleznogorsk, Russia), producing 15 mln.sq.m. monthly

- "Nizhkarton" Ltd. (Nijny Novgorod, Russia), producing 10 mln.sq.m. monthly

The use of the system enabled customers to reduce the material losses from 5-6 \% to $2-4 \%$, which amounts to saving of several hundred thousand euro per year, and also has noticeably reduced the production planning time - by 1.5-2 times.

Consideration of re-tuning of the finishing equipment while planning the cutting equipment operation remarkably reduces the number and duration of finishing equipment downtime periods. As a result, the total production line uptime is increased by 3-4\%.

In 2008 the "local" system was registered by the Foundation of algorithms and software of Russian Federal Agency for Education (Certificate №1640). In 2012 the web-based service was registered by Russian Federal Service for Intellectual Property, Patents and Trademarks (Certificate №2011618457).

In 2009 the System has won Golden medal of St.Petersburg Technical Fair in nomination "The best innovative and R\&D project of the year". In 2013 the webbased service has won Silver medal of St.-Petersburg Technical Fair in nomination "The best innovative and R\&D project of the year", and also diploma "The best innovative project of 2013" of Ministry of Economic Development of Karelia.

\section{B. The "Sawmill" system}

The aim of sawing process consists in processing round wood into sawn lumber, as well as technological wood chips. Typically a sawmill receives logs of various grades and diameters and sawn lumber is also divided according to sorts and sizes. The problem of sawing patterns calculation consists in specification of sizes and number of lumber to be cut from each log of given quality, length and diameter. As a rule, monthly plans cover more than 10 grade groups of logs and the number of produced sawn lumber grades is 50 or even 100 .

The plan contains quantity and size-qualitative structure of logs to be sawn and the lumber produced by applying each sawing pattern, taking into account all features, limitations and parameters of process equipment, as well as of raw material and production orders. The use of the service also improves the efficiency of calculating and correcting the operational plans.

The target of the service - with the use of advanced mathematical models and optimization algorithms of own development to solve a series of sawmill operation planning tasks for any number of orders and any configuration of process equipment.

The main functions of the service include:

- calculation and selection of cutting patterns,

- calculation of optimal plan, ensuring production of given specification of lumber from available (or expected) wood - either by maximal profit from the lumber, or by minimal use of wood,

- calculation of profitability of new orders in combination with existing production plan, and with possible new orders,

- calculation of optimal limits for log types (diameter groups) for sorting lines,

- calculation of optimal calendar plan in order to maximize the use drying and finishing equipment.

The developed mathematical model takes into account all known essential features, limitations and parameters of process equipment, of raw material and production orders.

The system has friendly and flexible user interface and can be easily modified to handle new customer-specific requirements.

The mathematical model of the production planning problem, its features and an overview of solution method for the related optimization problem are provided in [2].

The use of the system allows to increase overall mill productivity, output of high-quality grades of lumber and better matching the production specification. Overall increase of profitability - by 1-2 \%. More details are provided in the next section.

The efficiency of the system has been confirmed during 2011-2013 on real production data of 4 sawmills in Northwestern Russia: OJS «Medvezhegorsky sawmill», OJS «Segezhsky sawmill», OJS «Sokolsky DOK», CJS «Solomensky sawmill».

In 2012 the System was registered by Russian Federal Service for Intellectual Property, Patents and Trademarks (Certificate №2010617003). Also in 2012 the System has won Silver medal of St.-Petersburg Technical Fair in nomination "The best innovative and R\&D project of the year", and diploma "The best innovative project of 2012" of Ministry of Economic Development of Karelia. 


\section{The "Loading" system}

The paper rolls are transported in train carriages, trucks, and ships. In every case the vehicle must be loaded according to strict rules, the violation of which results in quality degradation and customer complaints. As the number of different types of rolls grows, and vehicle internal geometry becomes complicated, the order or loading of rolls into a vehicle may become relevant. As a result, the vehicle may carry less load than it could. The order of loading of rolls into a vehicle depends on vehicle geometry (the center of the roof of a railroad carriage is always higher than the walls), size and location of the gates (front or side), load balancing, etc. The number of possible combinations of rolls is inconceivable.

The service uses mathematical methods and different combinatorial, linear, dynamic and integer optimization algorithms to load more cargo into a set of vehicles, decrease the number of vehicles used, as well as to provide graphic presentation of cargo inside the vehicle.

The use of the service in many cases enables to increase by $5-10 \%$ the total weight of paper rolls loaded in a transportation vehicle. This enables to use less number of railroad carriages, trucks and containers. Also the planning time is noticeably reduced - by $1.5-2$ times.

The software system had been successfully installed at OJS "Bratsk pulp-and-board mill", OJS "Kondopoga pulpand-paper mill", OJS "Kotlas pulp-and-paper mill" (all - in Russia).

In 2008 the "local" system was registered by the Foundation of algorithms and software of Russian Federal Agency for Education (Certificate №1644). In 2013 the web-based service was registered by Russian Federal Service for Intellectual Property, Patents and Trademarks (Certificate №2013660036).

\section{The "Plywood" system}

The aim of the plywood production is to manufacture plywood sheets from in-stock veneer of different grade, thickness etc. [5]. Plywood is made from thin sheets of wood veneer (plies), which vary in thickness $1-3 \mathrm{~mm}$. Usually, 3, 5 or 7 plies of dimension $1.2 \times 2.4 \mathrm{~m}$ are glued together at right angles to each other to form the plywood panel, which can then be refinished. 4-5 quality grades of panels exist.

With hundreds of production orders received, thousands of plies already available (as well as timber logs for making new plies, if needed), there are thousands of feasible ways to obtain the sheets of required quality. Due to various limitations on the equipment operation, the planning must be made very carefully to meet the production and economical targets. This requires the use of specialized software based on mathematical methods and optimization algorithms.

Initial data for the plan includes available portfolio of orders for plywood production (including limits of allowable production output for each type, timing of orders, prices, currency rates etc.), as well as operational parameters (work schedule and standard productivity of equipment).

The computed plan contains the list of orders to be fulfilled during given time period (typically, a month), production output for each order, and way of composing plywood sheets of each type (if there are several options). It also contains the operation schedule of every production unit (press and hulling units), and raw materials required for fulfilling the orders, taking into account probability of appearance of veneer sheets of various grade, depending on basic materials and production technology.

Operation can be optimized either by production output (in cubic meters), or by expected profit (in rubles). Other criteria may be implemented, including more complex ones.

The mathematical methods and optimization algorithms used by the service enable to increase production by cost or volume (on average, by $+1.5 \%$ per month) by using existing plies more efficiently, as well as to simplify the planning procedures for the operators.

In 2008 the "local" system was registered by the Foundation of algorithms and software of Russian Federal Agency for Education (Certificate №1642). In 2013 the web-based service was registered by Russian Federal Service for Intellectual Property, Patents and Trademarks (Certificate №2013660037).

\section{E. The "Trim optimization" system}

Roll sets are produced by the winder from the parent reel. The "trim" (the width of the parent reel exceeding the width of the roll set) is a waste. With parent reel widths up to $10 \mathrm{~m}$, roll widths down to $50 \mathrm{~cm}$, and production orders including many different roll widths, there are thousands of ways to cut the parent reel to obtain the required rolls. Usually, there are 3-4 PM with different speed, parent reel width and density, and possibly paper quality. The production targets are set for entire mill, and paper grade change results in bad paper and lowers the total mill production. The service uses mathematical methods and optimization algorithms to plan the operation of several PMs to meet the production targets and minimize waste. Also the planning is simplified for the operators.

The target of the service - calculating the optimal distribution of orders between several paper machines for the purposes of increasing the productivity in given conditions, closest matching of production targets, decreasing of trim losses, decreasing of amount of downgraded paper.

The automation system has been installed at OJS 'Kondopoga' - one of 10 largest paper mills in Russia. The use of the system results in saving of $1.2 \%$ of paper per year. Considering the tons-per-year of paper production from a modern paper machine, even savings of $0.5 \%$ make this type of process control economically profitable. The 
other significant advantage is reduced time for production planning.

In 2008 the "local" system was registered by the Foundation of algorithms and software of Russian Federal Agency for Education (Certificate №1641).

\section{F. The software platform for optimal production planning}

Practical implementation of software systems for solving problems of optimal production planning requires development of a platform with a wide range of functionality to simplify and speed up software implementation and maintenance, as well as solution of optimization problems arising at industrial enterprises. Development of software systems for optimal planning and management of complex production processes of industrial enterprises on the basis of the platform is possible and efficient, because such systems typically use quite similar set of menus, forms, tables, dialog boxes and other components, as well as optimization algorithms [6].

It should be noted in this context that nowadays expert developers are required to implement cloud services [7]. Cloud Computing refers to both the applications delivered as services over the Internet and the hardware and systems software in the datacenters that provide those services [8]. Cloud computing can help small and medium business to lower their IT costs as the supported functionalities of software are no longer fixed or locked to the underlying infrastructure. This offers tremendous automation opportunities in a variety of computing domains [9].

Therefore, IT-park staff has developed a specialized platform [3] also for implementation of "cloud" services for optimal production planning at industrial enterprises. The main components of the "cloud" platform include (see Fig. 1):

- applications server, whose main part is business logic of software services, describing relevant subject areas,

- optimization server, including the library of modules for solution of optimization problems,

- file server, managing storing and joint access to files of various types,

- database server, managing storing, filling and changing data, as well as for providing information in response to the application server requests,

- audit server, managing complex monitoring of activity of various modules.

All platform components are integrated into MS Visual Studio.NET and can be freely and uniformly used together with standard methods and components of MS Visual Studio.

The main components of the platform for development of "desktop" or "local" systems are quite similar [6]. The

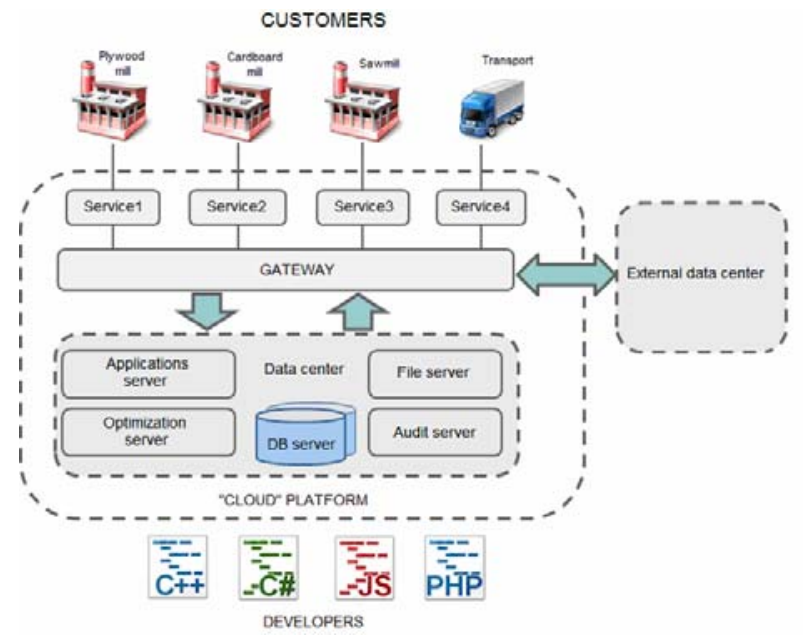

Fig. 1. The main components of the platform.

optimization server functionality is exactly the same, which is a great advantage.

IT-park continues improvement of existing systems and services for optimal planning at industrial enterprises, presented in this paper, as well as develops new services. IT-park specialists are also ready to customize them to specific demands of each Customer.

The use of unique mathematical models, methods and algorithms combined with modern software development platforms and methodologies enables IT-park specialists to offer products, which improve the productivity and profitability of key production processes of its Customers.

The strong mathematical and software development skills of IT-park developers also have served as a solid basis for establishing cooperation between PetrSU and a number of multinational corporations, examples of which are presented in the following sections.

\section{COOPERATION WITH METSO CORPORATION}

Cooperation between Metso Corporation [10], the global supplier of sustainable technology and services for mining, construction, power generation, automation, recycling and the pulp and paper industries, and PetrSU has been successfully developing since 1993 .

Metso has engineering, production, procurements, services business, sales and other operations in over 300 units in more than 50 countries. Worldwide Metso employs about 30000 professionals serving customers in more than 100 countries.

Metso's Automation business line specializes in process industry specialty analyzers and sensors, extensive automation and information management application networks and systems, and life cycle services. It also develops, produces and supplies control, on-off and emergency shutdown (ESD) valves as well as asset management solutions for various process industries. Its 
main customers are energy, power and oil and gas industries as well as the pulp and paper industry.

PetrSU and Metso have long-term strategic partnership agreement on software development, scientific research and specialists training. This allows combining the strong mathematical and software development background of PetrSU students and graduates and the leading position of Metso on the world market of automation systems.

Since 1994 PetrSU and Metso have been organizing the biennial international scientific and technical conference "New Information Technologies in the Pulp-and-Paper and Energy Industries", which is well-known to and is being visited by the representatives of all large pulp-and-paper mills of Russia.

Since 2001 PetrSU staff has participated in 32 automation projects for Russian enterprises such as Surgutneftegas, Sibur, Alrosa, largest pulp-and-paper mills, and other.

In 2002 this cooperation led to the establishment of joint PetrSU-Metso Automation Systems Center (PMASC). At PMASC more than 30 programmers are developing software for Metso automation systems, which is then delivered to customers all over the world.

Since 2004, the Training Center for Metso, the only in Russia and one of 6 in the world, operates at PetrSU. By now, the training has been given to more than 600 specialists from more than 30 Russian companies, including the leading ones such as Surgutneftegas, Sibur, Rosneft, Norilsky Nickel and many others. The equipment and training programs are also used for PMASC staff and PetrSU student training.

In 2009 local branch office of ZAO "Metso Automation" was established in Petrozavodsk with the purpose of further improving the efficiency of collaboration between PetrSU and research and development departments of Metso. This confirms the intention of both parties to continue and expand cooperation.

\section{COOPERATION WITH OUTOTEC CORPORATION}

Cooperation between Outotec [11], the global supplier of sustainable technology and services that support the entire life cycles of processes, including their operation and maintenance in two business areas (Minerals Processing and Metals, Energy \& Water), and PetrSU has been successfully developing since 2008 .

Computer-aided modeling is used widely in modern engineering, and that is true also for chemical engineering. Modeling of chemical processes allows developing new technological processes in a cheaper, faster and safer way, than traditional experimentation-based engineering.

There are many different models of chemical processes, but in every case it is necessary to account for thermodynamics, i.e. for the composition of the system once it reaches the thermodynamic equilibrium. Computation of the thermodynamic equilibrium is a complex mathematical problem, especially when species with near-zero amounts must be taken into consideration.

Outotec uses equilibrium calculations as a part of their HSC Chemistry software package (www.hscchemistry.net/ ) that is actively used for process engineering, research and education - it has been delivered to more than 1,500 customers in 76 countries.

PetrSU has developed a new equilibrium calculation module that provides greater calculation accuracy and stability that its predecessors. The new Gibbs Energy Minimization algorithm (GEM) not only improve the calculation results themselves, but also allows to model non-ideal chemical systems, open chemical systems and systems with additional constraints. The module has been included as a part of HSC Chemistry 7.1 release. The advanced calculation modes using GEM, as well as related user interface improvements are now being finalized for HSC Chemistry 8 release.

\section{COOPERATION WITH NOKIA RESEARCH CENTER AND FRUCT OY}

Cooperation between PetrSU and Nokia Research Center started in 2006. The joint activities include student training, research and development of software for mobile devices, mainly open-source, with special focus being made in particular on e-Health, and Smart Spaces.

In 2006 Nokia has initiated establishment of an open innovations association FRUCT (Finnish-Russian Universities Collaboration in Telecommunications), which since 2010 is managed by a small company FRUCT Oy [12].

In 2008 PetrSU became an active member of FRUCT, and also the Laboratory of mobile and wireless technologies and applications was founded at PetrSU with the support of Nokia.

Since 2010 PetrSU and FRUCT, together with selected partners, implement several grants of Karelia ENPI - joint program of European Union, Russia and Finland [13].

During 2011-2014 the project KA179 "Complex development of regional cooperation in the field of open ICT innovations" is being implemented with Center of Internet Excellence of University of Oulu. The overall objective of the project is to create and further develop the ICT competence incubation infrastructure and a set of wellprepared teams, capable to perform independent challenging research, development and entrepreneurship activity with possible future implementation in industry. As a result, the created teams will have clear focus on contributing to measurable and demanded industry-relevant outcome, up-to-date competences and equipment, as well as good visibility.

During 2012-2014 the project KA322 "Development of cross-border e-tourism framework for the programme region (Smart e-Tourism)" is being implemented with University of Oulu, St.Petersburg Institute for Informatics and Automation of the Russian Academy of Sciences, and 
Tourism Information Center of Karelia. The overall objective of the project is to contribute to increasing the inflow of "organized" tourists to the region, maximizing the use of regional tourism infrastructure and services, and marketing the programme area for tourists from other regions and countries with the help of advanced information and Internet technologies.

During 2013-2014 the project KA432 "Journey planner service for disabled people (Social Navigator)" is being implemented with University of Oulu, and Ministry of Health and Social Development of Karelia. The overall objective of the project is to improve quality of life of persons with disabilities by improving their personal mobility, access to a range of in-home, residential and other community support services, which will support their inclusion in the community, and prevent isolation or segregation from the community through the use of advanced user-friendly ICT services.

One of the applications, developed jointly with FRUCT during implementation of project KA179, - "CardiaCare" has won Russian Mobile VAS award in 2012, as well as Golden medal of St.-Petersburg Technical Fair in nomination "The best innovative and R\&D project of the year" in 2013.

\section{CONCLUSION}

The status of IT-park as a unit of PetrSU gives a unique opportunity to create project teams including both experienced developers (doctors and candidates of science), and young graduates, post-graduates, and senior year students. This creates the innovative concept "ITconveyor": young students attend courses, given by instructors with practical experience, then at senior years they start to work in projects, and after graduation some of them in addition to project work teach students thus sharing their practical experience with them.

This early and gradual involvement of students into practical projects results to training of specialists, who are able to work in industry in challenging and complex customer and/or research projects. Many PetrSU graduates continue to work at IT-park.

Training of modern IT-specialists of international level requires developing multi-cultural ICT-expertise. At PetrSU this is achieved within the framework of cooperation with universities and companies of Nordic countries and Finland in the first place.

Currently in Russia there is a shortage of high-skilled IT-specialists. The absolute majority of the largest ICTcompanies are located in Moscow and St.-Petersburg, which creates a serious threat of "brain drain" of ITspecialists from companies and universities of Karelia to these cities. To keep professional human resources in the region, an appropriate infrastructure is required - financial, career, professional and social. To ensure that, Karelia needs to build upon its advantages - status of a scientific and a university center, geographical location on EU border and Finland, which is well-known for advances in innovations and ICT-industry, as well as lower living and office running costs compared to St.-Petersburg and Moscow regions. Close partnering of PetrSU with industry provides challenging and concrete research tasks and additional resources, which attract youth thus helping to solve the human resource problem in the whole region.

Implementation of customer and research projects requires IT-park staff to master and use advanced development platforms, approaches, tools for code analysis, performance monitoring, automated testing, design patterns, integration, stable builds, etc. All software lifecycle stages are covered - development, commissioning and training. The range of problems being solved varies from enterprise management to mobile applications and games.

Over the years, PetrSU has developed experience, infrastructure and necessary resources for efficient cooperation with foreign partners, and now successfully collaborates with the leading Finnish, Russian and international companies - the world leaders in innovations, - as well as small and medium-sized enterprises. Also the strategic development program of PetrSU had been supported by the Government of Russia and is being implemented.

\section{REFERENCES}

[1] A. V. Voronin and V. A. Kuznetsov, Mathematical models and methods of planning and managing pulp and paper factory. Petrozavodsk, PetrSU, 2000. (in Russian).

[2] A. V. Voronin, V. A. Kuznetsov, A. I. Shabaev, and I. V. Arkhipov, "Software system for sawmill operation planning". $\mathrm{SPb}$.: Proceedings of 12th conference of Open Innovations Association FRUCT, 2012. pp. 165-171.

[3] D. P. Kositsyn, V. A. Kuznetsov, and A. I. Shabaev, "Optimal planning software platform development with cloud computing technology". SPb.: Proceedings of 12th conference of Open Innovations Association FRUCT, 2012. pp. 129-135

[4] R. V. Soshkin. Optimal corrugated cardboard cutting problems and methods of their solution, Ph.D. thesis, Petrozavodsk: PetrSU, 2009 (in Russian)

[5] A. A. Veselov, L. G. Galyk, Y. G. Doronin et al. Reference book of plywood production (ed. N. V. Kachalin), Moscow: Forest industry, 1984 (in Russian).

[6] A. V. Voronin, A. I. Shabaev, and A. A. Pechnikov, "Pipelined technology of software development for the management of production resources and processes", Prospects of Science, vol. 4. pp. 95-99, 2010 (in Russian).

[7] R. Buyya, J. Broberg, and A. Goscinski, Cloud Computing: Principles and Paradigms, New York: John Wiley \& Sons, 2010.

[8] M. Armbrust and A. Fox. (2009). Above the Clouds: A Berkeley View of Cloud Computing, University of California at Berkeley. Available: http://www.eecs.berkeley.edu/Pubs/TechRpts/2009/ EECS -2009-28.pdf.

[9] L. Wang, R. Ranjan, and J. Chen, Cloud Computing: Methodology, Systems, and Applications, London: Taylor \& Francis Group, 2012.

[10] Metso Corporation official web-site. Web: www.metso.com.

[11] Outotec Corporation official web-site. Web: www.outotec.com.

[12] FRUCT Oy official web-site. Web: www.fruct.org.

[13] Karelia ENPI official web-site. Web: www.kareliaenpi.eu. 